\title{
Polychlorinated naphthalenes in Great Lakes air: assessing spatial trends and combustion inputs using PUF disk passive air samplers
}

Tom Harner $^{\mathrm{a}^{*}}$, Mahiba Shoeib ${ }^{\mathrm{a}}$, Todd Gouin ${ }^{\mathrm{a}}{ }^{\mathrm{b}}$, Pierrette Blanchard $^{\mathrm{a}}$

${ }^{a}$ Science \& Technology Branch, Environment Canada, 4905 Dufferin Street, Toronto, ON, M3H 5T4

${ }^{\mathrm{b}}$ University of Toronto at Scarborough, Dept. of Physical and Environmental Sciences, 1265 Military

Trail, Toronto, ON M1C 1A4

Supplementary Information

1 figure summarizing the EF values for combustion PCNs for each sampling period Air trajectory probability density maps for TNT and STC

5 pages 

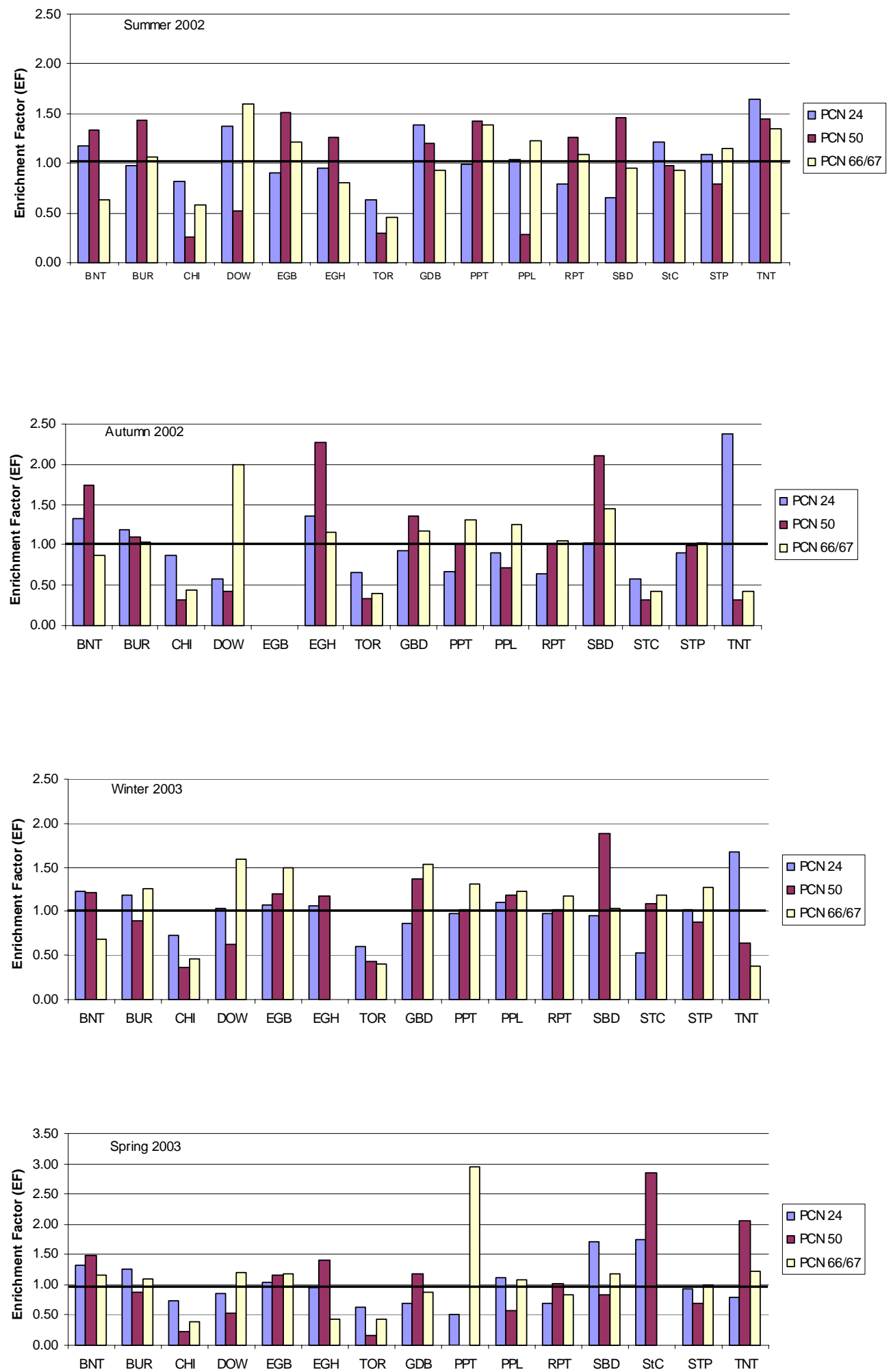

Figure S1: EF values of the combustion marker PCNs for each of the sampling periods 
Backward air trajectory probability density maps representing the airsheds for each of the sampling periods at TNT and STC

Back Trajectory Calculations. Three-day back trajectories for each of the individual sites were calculated at 10,100 and $500 \mathrm{~m}$ above ground level at $6 \mathrm{~h}$ intervals for each day the PAS were deployed using the Canadian Meteorological Centre (CMC) Trajectory Model. Thus, depending on the deployment period at an individual site, between 186 and 333 back trajectories were calculated for each sample, generating some 2500 different endpoints. This information was used to produce back trajectory probability maps, which are useful in qualitatively identifying those regions where the parcels of air arriving at the site were most frequently associated with.

(Note: Density maps for all other sites are available in the Supplementary Information in:

Gouin, T., Harner, T., Blanchard, P., Mackay, D. Passive and active air samplers as complementary methods for investigating persistent organic pollutants in the Great Lakes basin. Environmental Science \& Technology 39, 9115-9122 (2005)). 


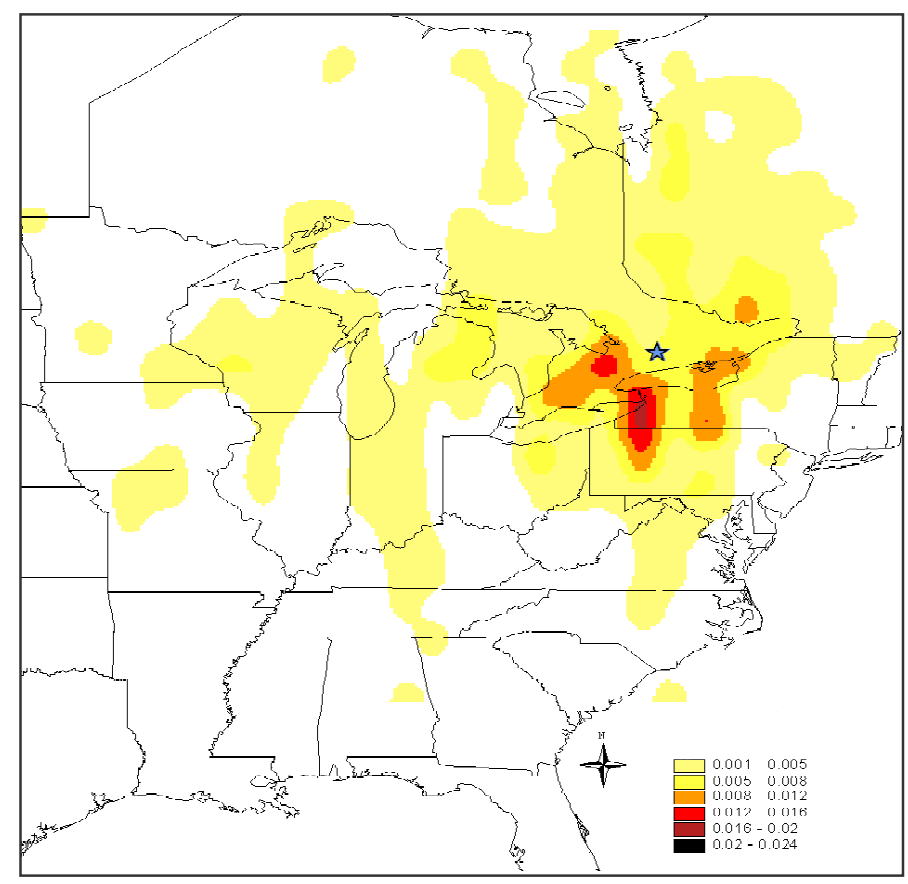

Trent University - Summer 2002

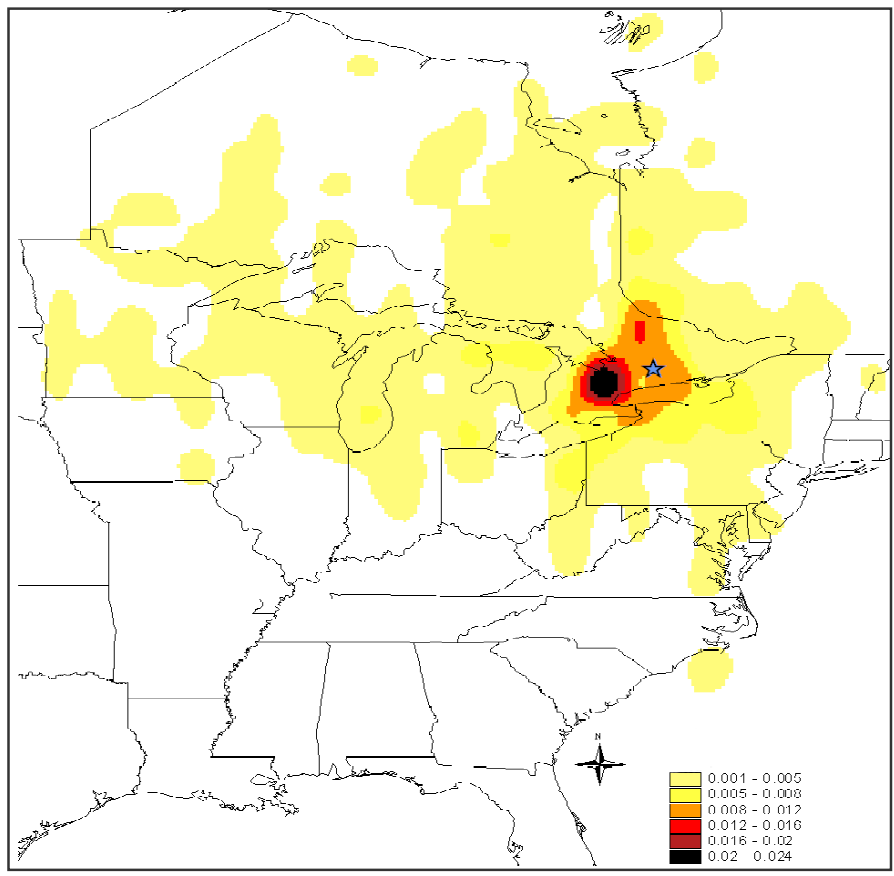

Trent University - Winter 2003

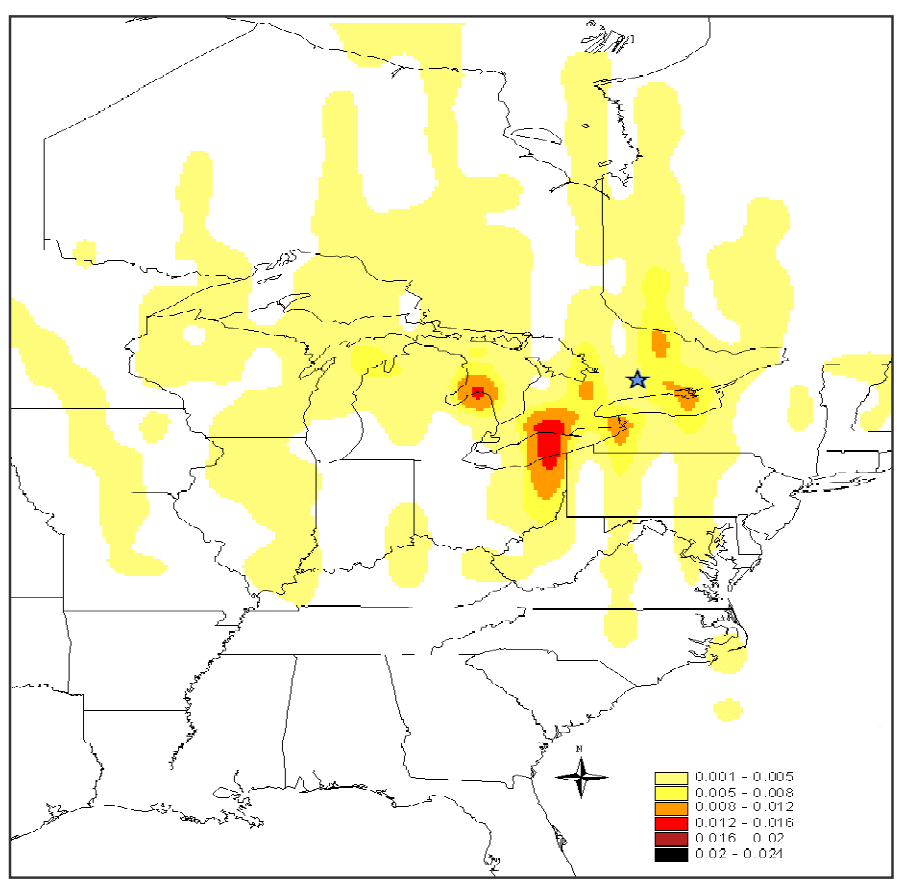

Trent University - Autumn 2002

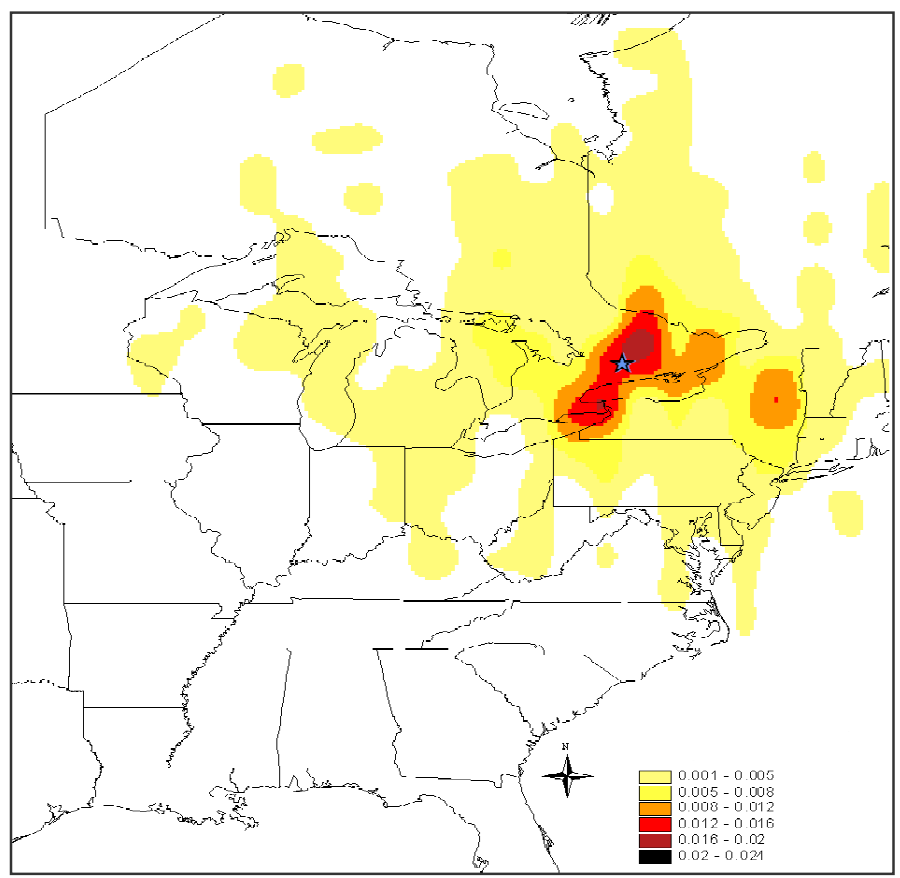

Trent University - Spring 2003 


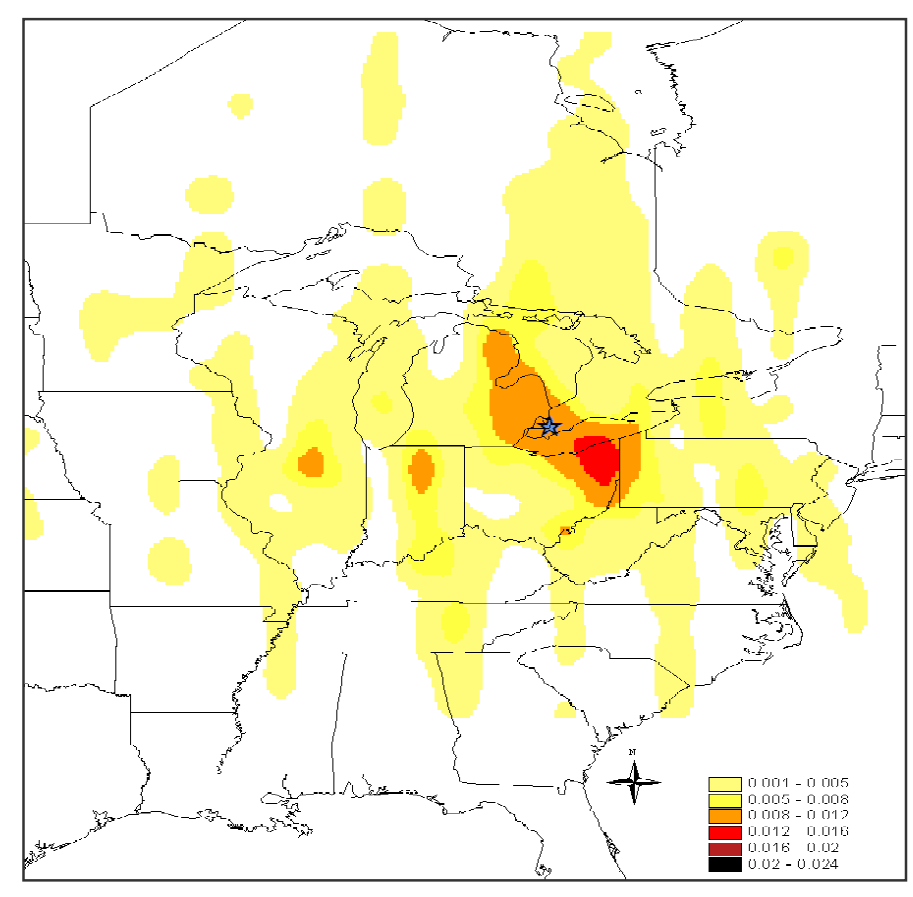

St. Clair - Summer 2002

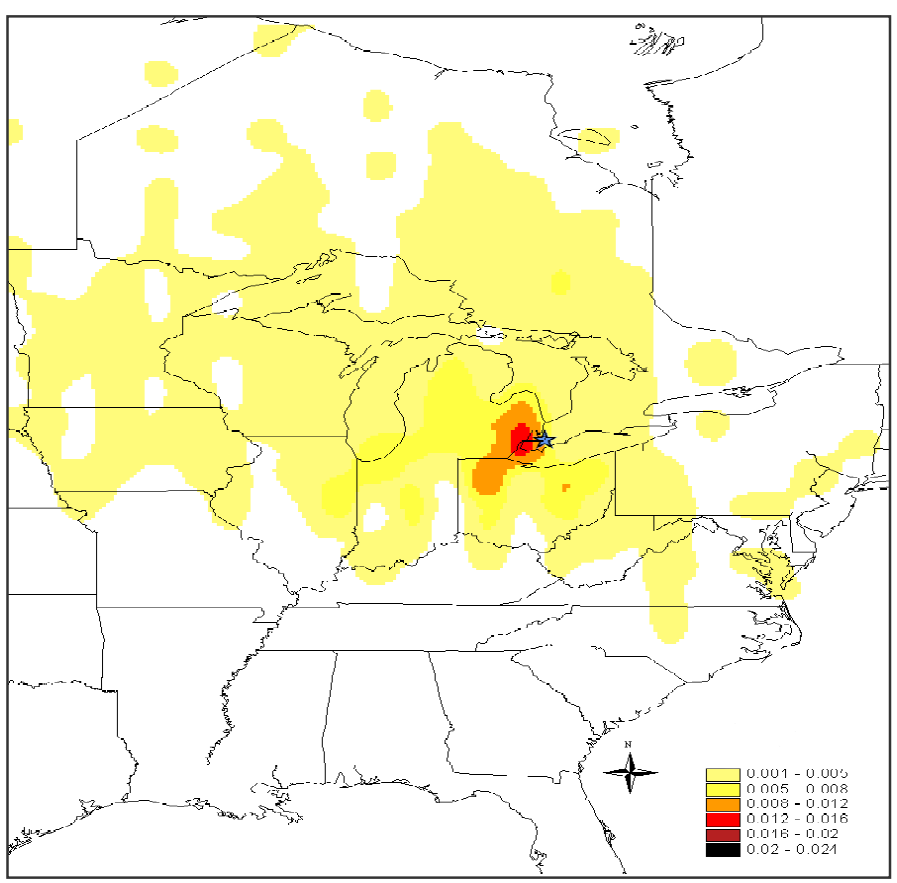

St. Clair - Winter 2003

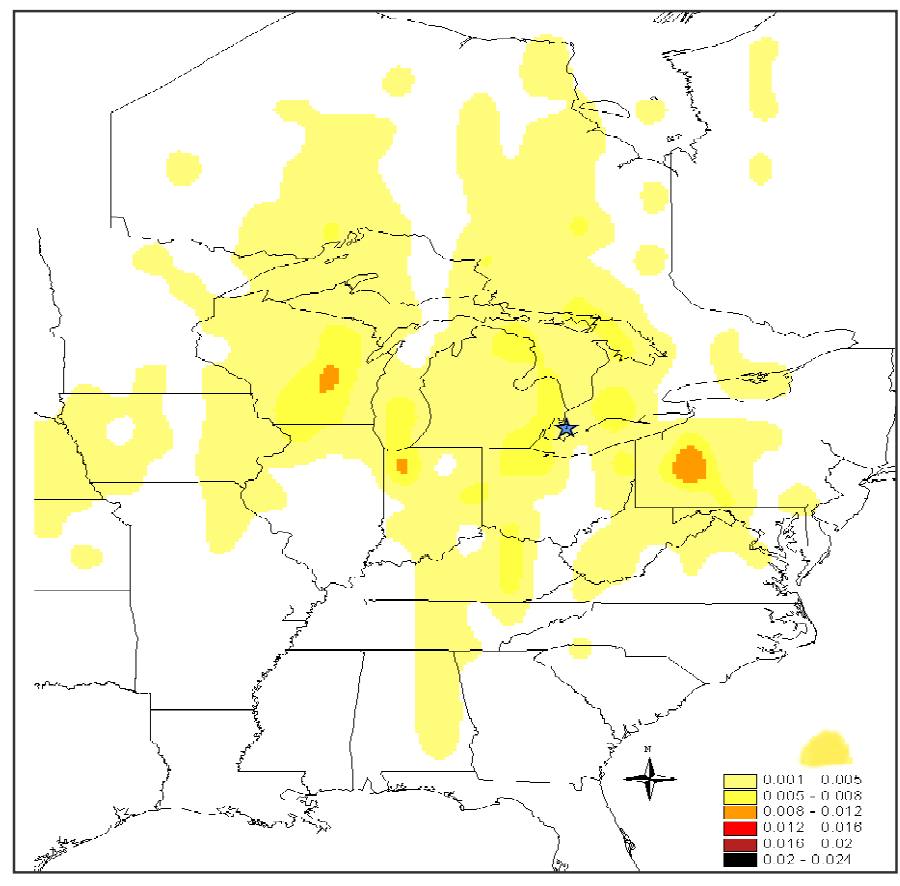

St. Clair - Autumn 2002

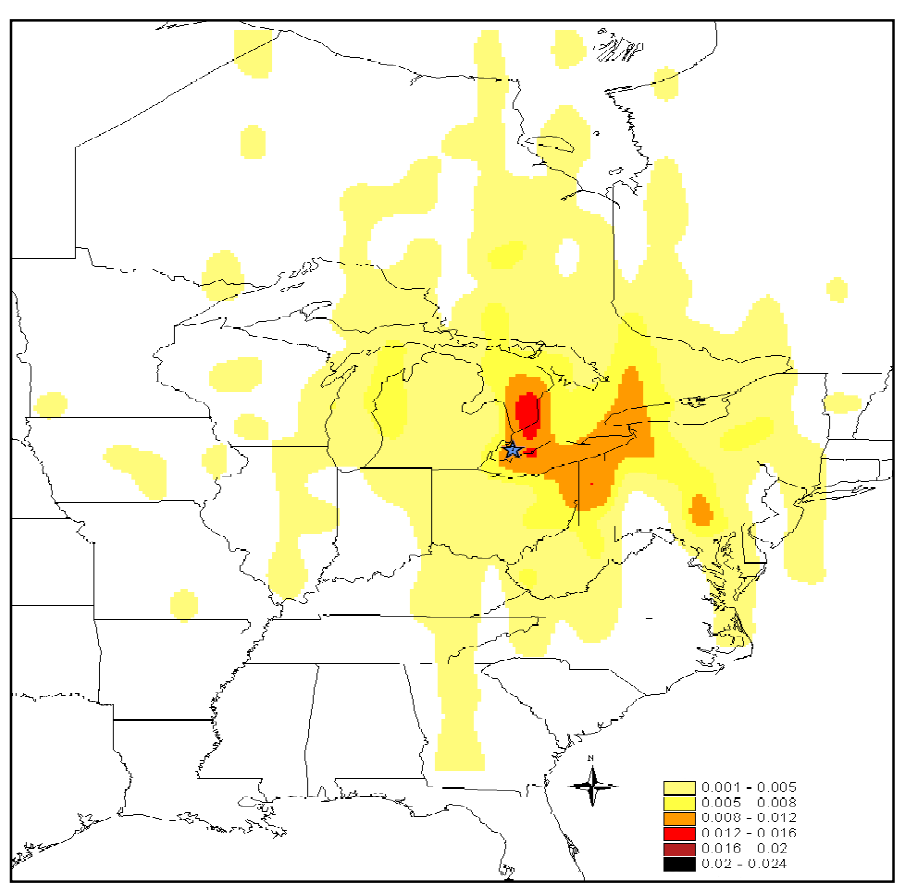

St. Clair - Spring 2003 